\title{
Relationships of Big Five personality traits and nonverbal intelligence at high school age
}

\author{
Irina Voronina ${ }^{1,}{ }^{*}$, Alexander Fenin ${ }^{1}$, Tamara Malykh ${ }^{1}$ and Alexandra Belova ${ }^{1}$ \\ ${ }^{1}$ Psychological Institute of Russian Academy of Education, 125009, Moscow, Russia
}

\begin{abstract}
The article presents the results of study on the relationship of personality traits and intelligence in Russian high school students. The study focused on Big Five personality traits - Neuroticism, Extraversion, Openness, Agreeableness and Conscientiousness - and the structure of their relationships with nonverbal intelligence, as measured by the test "Standard Progressive Matrices". Significant correlations were only found between nonverbal intelligence and Openness $(r=0.26, p<0.05)$. The results are interpreted in the context of investment theory, which assumes that personality traits can promote the formation of individual differences in intelligence.
\end{abstract}

\section{Introduction}

Personality traits and intelligence are associated with the formation of individual differences in a range of lifetime achievements - from school to professional results [1-3]. Therefore, the relationship of these constructs has been of great interest to researchers.

Despite the fact that intelligence and personality are usually considered independently of one another, these two constructs have a lot in common [4]. In particular, both personality and intelligence are latent psychological characteristics [5], their effect is manifested in behavioral differences [6], and these differences can be measured by standardized psychometric instruments [7].

On the one hand, there is a weak or zero correlation between personality traits and psychometric intelligence $[4,8]$. On the other hand, more and more researchers have detected significant correlations between personality traits and intelligence, especially among the Big Five personality traits and nonverbal intelligence [4, 9-12].

Among the Big Five traits, Openness shows the strongest association with nonverbal intelligence [12,13]. This relationship is confirmed in the pilot study on the sample of Russian girls [14]. A possible explanation for this stable relationship reproduced in many studies is that people, who are more open to experience, more actively participate in various types of intellectual activities from reading literature to visiting scientific and educational events. This fact contributes to the accumulation of knowledge which is manifested, in particular, in achievement tests [11].

The second reproducible relationship is between Neuroticism and intelligence [9]. The three components of this personality trait - Anxiety, Anger and Hostility are negatively related with psychometric intelligence with correlations varying from -0.15 to -0.33 [9].
Extraversion also shows significant correlations with intelligence, but significantly lower than Neuroticism [4]. However, this correlation is not always replicated. In particular, the studies report significant correlations of 0.08 [9] to 0.20 [15] as well as the absence any association between Extraversion and psychometric intelligence [11].

Agreeableness and Conscientiousness, as a rule, are not associated $[9,12]$ or show weak correlation with nonverbal intelligence [16]. One study found a negative relationship of Conscientiousness and intelligence, which is interpreted in the context of compensatory mechanisms [17].

In general, according to research, three of the five main dimensions of personality - Openness to experience, Neuroticism and Extraversion - are interrelated to a different extent with nonverbal intelligence.

However, most studies of the relationship of personality traits and intelligence are conducted on samples of adults and students due to age restrictions of the Big Five questionnaire. There are few studies on samples of school children, in which adapted Big Five personality questionnaire was used [18].

At the same time, previous studies identified agerelated features of personal characteristics and nonverbal intelligence, which may condition the specificity of the relationship of personality traits and intelligence at school age [19]. In the study on the Russian sample of high school students no relationship between the personality traits and non-verbal intelligence was found [14]. At the same time, after separating the sample by gender a moderate correlation of Openness to experience with intelligence was found only on a sample of girls [14].

\footnotetext{
Corresponding author: irina.d.voronina@gmail.com
} 
The current study aimed to analyze the relationship of Big Five personality traits with nonverbal intelligence on the extended sample of high school students.

\section{Methods}

\subsection{Participants}

The study involved 504 high school students, including 254 female $(50.4 \%)$ and 250 male students (49.6\%), aged between 14 and 18 years (median age $=15.5$ years, $\mathrm{SD}=1.1)$. Consent forms were obtained from parents. Data collection was anonymous - each participant was assigned a personal identification number.

\subsection{Procedure}

'Standard Progressive Matrices' test was used to assess nonverbal intelligence. The test consists of 60 tasks with increasing complexity, grouped in 5 series (A to E).

To assess personality traits, we used the Russian version of the questionnaire NEO-PI-R, standardized on the Russian population. The questionnaire is based on the five-factor model of personality [20]. Each of the five scales includes 6 subscales, or facets, each assessed on the basis of 8 questions.

\section{Results and discussion}

Table 1 shows the descriptive statistics for the analyzed personality traits - Neuroticism, Extraversion, Openness to experience, Agreeableness, Conscientiousness.

Table 1. Descriptive statistics for NEO-PI-R.

\begin{tabular}{|c|c|c|c|}
\hline Scale & Mean & SD & $\begin{array}{c}\text { Cronbach's } \\
\text { alpha }\end{array}$ \\
\hline Neuroticism & 93.8 & 18.9 & 0.79 \\
\hline Extraversion & 112.8 & 21.2 & 0.82 \\
\hline Openness & 111.1 & 17.6 & 0.75 \\
\hline Agreeableness & 101.3 & 17.4 & 0.78 \\
\hline Conscientiousness & 106.3 & 18.8 & 0.86 \\
\hline
\end{tabular}

According to Table 1, Cronbach's alphas obtained on a sample of high school students reach satisfactory values for all scales: from 0.75 to 0.86 . This confirms the reliability of the scales of the personality questionnaire NEO-PI-R.

Table 2 shows the descriptive statistics for the performance on the series A, B, C, D, E, and the total score on the test 'Standard Progressive Matrices'.

Table 2. Descriptive statistics for series A to E of the test 'Standard Progressive Matrices'.

\begin{tabular}{|l|c|}
\hline Series & Mean $(\mathrm{SD})$ \\
\hline A & $11.6(0.6)$ \\
\hline B & $11.3(0.7)$ \\
\hline C & $9.8(1.5)$ \\
\hline D & $9.8(1.4)$ \\
\hline E & $6.7(2.7)$ \\
\hline Total & $49.1(5.5)$ \\
\hline
\end{tabular}

Table 2 shows the average number of correct answers on the test series. The maximum value for each series is 12 points, minimum - 0 points. The maximum total score can reach 60. A decrease in mean values from series A to series E confirms the increasing complexity of the test tasks. The scores for the series A and B almost reach the maximum value, therefore, demonstrating the 'ceiling effect'. The standard deviations for these series are the lowest, which also confirms the lack of difficulty in solving tasks of this series at high school age. The lowest average value obtained for E series is 6.7 out of 12 . This shows the complexity of the tasks that require analytical and synthetic thinking.

Correlation analysis was performed to examine the relationship of personality traits and nonverbal intelligence. Table 3 presents the Pearson correlation coefficients between the Big Five personality traits Neuroticism (1), Extraversion (2), Openness to experience (3), Agreeableness (4), Conscientiousness (5) - and nonverbal intelligence on the sample of high school students.

Table 3. Correlations between the Big Five personality traits and nonverbal intelligence.

\begin{tabular}{|l|c|c|c|c|c|c|}
\hline & $\mathrm{A}$ & $\mathrm{B}$ & $\mathrm{C}$ & $\mathrm{D}$ & $\mathrm{E}$ & Total \\
\hline$(1)$ & -0.02 & 0.02 & 0.05 & -0.06 & -0.01 & 0.01 \\
\hline$(2)$ & -0.08 & 0.03 & -0.11 & 0.04 & 0.05 & -0.03 \\
\hline$(3)$ & 0.04 & $0.23^{*}$ & 0.07 & 0.18 & $0.27^{*}$ & $0.26^{*}$ \\
\hline$(4)$ & -0.12 & -0.02 & -0.04 & -0.02 & 0.01 & -0.02 \\
\hline$(5)$ & -0.02 & 0.05 & -0.10 & 0.07 & 0.03 & 0.01 \\
\hline
\end{tabular}

According to Table 3, only Openness was associated with the indicators of non-verbal intelligence. This personality trait correlates with successful performance in a series $\mathrm{B}$ with tasks that assess the ability to find analogies $(r=0.23, p<0.05)$ and $E$, assessing analytical and synthetic thinking as a whole $(\mathrm{r}=0.27, \mathrm{p}<0.05)$. The total score on the test of nonverbal intelligence showed moderat correlation with Openness $(\mathrm{r}=0.27, \mathrm{p}<$ $0.05)$.

The correlation analysis carried out for the subscales within Openness showed that the total score for nonverbal intelligence was associated with Feelings ( $\mathrm{r}=$ $0.22, \mathrm{p}<0.05)$ and Fantasy $(\mathrm{r}=0.21, \mathrm{p}<0.05)$. Correlations of other Big Five personality traits with indicators of nonverbal intelligence (both the series and the total score) did not exceed 0.1.

Thus, it seems that the only Big Five factor associated with nonverbal intelligence in high school students is Openness to experience. These results are consistent with the data obtained on adult samples [12, 21]. A possible explanation for this almost unanimous relationship is provided by the investment theory, which assumes that personality traits can promote the formation of individual differences in intelligence [4, 9, 22]. According to publications, people with high levels of Openness are more likely to engage in activities aimed at the acquisition of knowledge [23, 24]. For example, on a sample of students aged 17 to 23 years it was shown that one of the aspects of the 'academically-oriented behavior' - smart investment - was closely related to Openness [23]. In another study, on a sample of schoolage children a strong positive relationship between Openness and involvement in intellectual activities was found [22]. 


\section{Conclusion}

The current study has shown that the structure of the relationship of the Big Five personality traits and nonverbal intelligence at high school age in general is different from the relationship of these psychological constructs in adults. However, the direction of the causal relations in the dyad Personality - Intelligence can be only empirically verified in a longitudinal study. It seems promising to analyse the structure of personality traits and their relationships with intelligence at primary school age and in adolescence. We have already made the first step in this direction - the adaptation of the Russian version of the personality questionnaire 'Big Five - children's version' intended for school children aged 9 - 14 years [25].

\section{Acknowledgements}

This study was supported by the grant from the Russian Science Foundation (grant RSF № 14-18-03764).

\section{References}

1. T. Chamorro-Premuzic, A. Furnham, J. of Res. in Pers. 37, 319 (2003)

2. L.S. Gottfredson, Hum. Perf., 15, 25 (2002)

3. N.R. Kuncel, S.A. Hezlett, D.S. Ones, J. of Pers. and Soc. Psyc., 86, 148 (2004)

4. S.B. Malykh, T.N. Tikhomirova, Voprosy psikhologii [Psychological issues], 2, 147 (2015)

5. T. Chamorro-Premuzic, A. Furnham, Personality and intellectual competence (Psychology Press, 2014)

6. J. Brebner, C. Stough, in International handbook of personality and intelligence, 321 (Springer US, 1995)

7. D.C. Funder, Accuracy in personality judgment: Research and theory concerning an obvious question (2001)

8. J. Moutafi, A. Furnham, J. Crump, Eur. J. of Pers., 17, 79 (2003)
9. P.L. Ackerman, E.D. Heggestad, Psyc. bul., 121, 219 (1997)

10. E.J. Austin, S.M. Hofer, I.J. Deary, H.W. Eber, Pers. and Ind. Dif., 29, 405 (2000)

11. T. Chamorro-Premuzic, J. Moutafi, A. Furnham, Pers. and Ind. Dif., 38, 1517 (2005)

12. A. Furnham, J. Moutafi, T. Chamorro-Premuzic, Int. J. of Sel. and Assessm., 13, 11 (2005)

13. P.C.L. Heaven, J. Ciarrochi, Pers. \& Soc. Psyc. Bul., 34, 451, (2008)

14. S.B. Malykh, I.A. Voronin, V.I. Ismatullina, I.M. Zakharov, T.N. Tikhomirova, Teoreticheskaya i eksperimentalnaya psikhologiya [Theoretical and experimental psychology], 7, 17 (2014)

15. R. Lynn, S. Hampson, M. Magee, Pers. and Ind. Dif., 5, 549 (1984)

16. P. Kyllonen, in Handbook on testing, 347 (Westport, CT, US: Greenwood Press, 1997)

17. J. Moutafi, A. Furnham, L. Paltiel, Pers. and Ind. Dif., 37, 1013 (2004)

18. K. Laidra, H. Pullmann, J. Allik, Pers. and Ind. Dif., 42, 441 (2007)

19. T.N. Tikhomirova, A.D. Modyaev, N.M. Leonova, S.B. Malykh, Psikhologicheskii Zhurnal [Psychological journal], 36, 43 (2015)

20. J.P.T. Costa, R.R. McCrae, Pers. and Ind. Dif., 13, 653 (1992)

21. P.C. Heaven, J. Ciarrochi, Pers. and Ind. Dif., 53, 518 (2012)

22. A.J. Gow, M.C. Whiteman, A. Pattie, I.J. Deary, Pers. and Ind. Dif., 39, 317 (2005)

23. D.A. Briley, M. Domiteaux, E.M. Tucker-Drob, Learn. and Ind. Dif., 32, 26 (2014)

24. T.C. Bates, A. Rock, Intelligence, 32, 33 (2004)

25. S.B. Malykh, T.N. Tikhomirova, G.M. Vasin, Teoreticheskaya i eksperimentalnaya psikhologiya [Theoretical and experimental psychology], 8 (2015) 